\title{
Oxygen Reduction Reaction at in Situ Fabricated Active Gold Over Layers in Acidic Media
}

\author{
Md. Rezwan Miah ${ }^{1, *}$, Takeyoshi Okajima ${ }^{2}$, Takeo Ohsaka, \\ ${ }^{1}$ Department of Chemistry, School of Physical Sciences, Shahjalal University of Science and \\ Technology, Sylhet-3114, Bangladesh \\ ${ }^{2}$ Department of Chemical Science and Engineering, School of Materials and Chemical Technology, \\ Tokyo Institute of Technology, 4259-G1-5 Nagatsuta, Midori-ku, Yokohama 226-8502, Japan \\ ${ }^{3}$ Research Institute for Engineering, Kanagawa University, 3-27-1 Rokkakubashi, Kanagawa-ku, \\ Yokohama 221-8686, Japan \\ *E-mail: mrmche@yahoo.com, pt120866sa@kanagawa-u.ac.jp
}

doi: $10.20964 / 2016.09 .30$

Received: 13 May 2016 / Accepted: 1 July 2016 / Published: 7 August 2016

Hydrous gold (Au) oxide, on polycrystalline $\mathrm{Au}(\mathrm{Au}$ (poly)) electrode was in situ electrogenerated by multi-potential step amperometric (MPSA) technique between $2.2 \mathrm{~V}$ and $0.8 \mathrm{~V}$ with pulse time $0.001 \mathrm{~s}$ at each potential in $0.5 \mathrm{M} \mathrm{H}_{2} \mathrm{SO}_{4}$ solution for different times between 5-60 s. Electrodes with active gold over layers (agol) on the $\mathrm{Au}$ (poly) electrode (agol $\mid \mathrm{Au}$ (poly)) were generated by electroreduction of the hydrous $\mathrm{Au}$ oxide formed by MPSA technique. The agol $\mid \mathrm{Au}$ (poly) electrodes were characterized by reductive desorption of cysteine self-assembled monolayer (Cyst-SAM) and oxidative stripping of electrodeposited $\mathrm{Pb}$. The in situ fabricated agol $\mid \mathrm{Au}$ (poly) electrode surface was found to be enriched in $\mathrm{Au}(100)$ and $\mathrm{Au}(110)$ domains as compared with the untreated $\mathrm{Au}$ (poly) electrode. Oxygen reduction reaction at the agol $\mid \mathrm{Au}$ (poly) electrode was carried out in $0.5 \mathrm{M} \mathrm{H}_{2} \mathrm{SO}_{4}$ solution. A significant catalysis of the ORR was achieved. The catalytic properties were explained in terms of crystalline domains and roughness factor of the Au electrode.

Keywords: Hydrous Au oxide; Active gold over layers; Roughness factor; Single crystalline domain; Oxygen reduction reaction

\section{$\underline{\text { FULL TEXT }}$}

(C) 2016 The Authors. Published by ESG (www.electrochemsci.org). This article is an open access article distributed under the terms and conditions of the Creative Commons Attribution license (http://creativecommons.org/licenses/by/4.0/). 